\title{
KINETICS AND DYNAMICS OF OXIDATION REACTIONS INVOLVING AN ADSORBED CO SPECIES
}

\author{
Michael P. Haruld \\ W. Curtis Conner \\ Department of Chemical Engineering \\ University of Massachusetts, Amherst, MA 01003 \\ Second Year Annual Report \\ Period: $1 / 1 / 92 \cdot 12 / 31 / 92$ \\ Support by U.S. Department of Energy \\ Office of Basic Energy Sciences \\ Chemical Sciences Division \\ Grant no. DE-FG02-87ER13772
}

July, 1992

Project Duration: Three years

Type of Business: Non-profit
Starting Date: 1/1/91

Budget: $\$ 217,000$

\section{Principal Investigator: Michael P. Harold \\ Associate Professor of Chemical Engineering \\ Co-Investigator: \\ W. Curtis Conner \\ Associate Professor of Chemical Engineering \\ Business Contact: Dorothy Baronas \\ Acting Director, Office of Grants and Contracts \\ DISCLAIMER}

\begin{abstract}
This report was preparod as an account of work sponsorod by an agency of the United States Government. Neither the United States Government nor any agency thereof, nor any of their ermployees, makes any warranty, express or implied, or assumes any legal liability or responsibility for the accuracy, completeness, or usefulness of any information, apparatus, product, or process disclosed, or represents that its use would not inlringe privately owned rights. Reference herein to any specific commercial p:oduct, process, or service by trade name, trademark, manufacturet, or otherwise does not nectssarily constitute or imply its endorsement, recommendation, or favoring by the United States Government or any agency thereof. The vicws and opinions of authors expressed herein do not necessarily state or reflect those of the United Stater Government or any agency thereor.
\end{abstract}

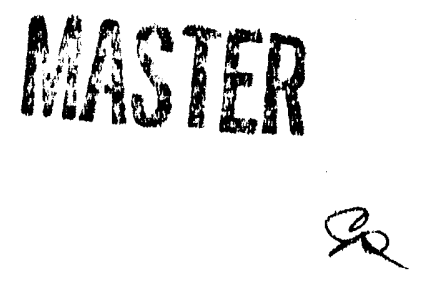




\section{Research Scope and Objectives}

This project focuses on oxidation reactions in which $\mathrm{CO}$ is a key player - be it a reactant, adsorbed intermediate, and/or partial oxidation product - in the catalytic sequence and chemistry. Reaction systems studied include $\mathrm{CO}$ and methanol oxidation by $\mathrm{O}_{2}, \mathrm{CO}$ oxidation by $\mathrm{NO}$, and ethylene oxidation by $\mathrm{O}_{2}$, on both noble metal and metal oxide catalysts. Each of these reactions are known to exhibit complex steady state and dynarnic behavior, such as multiple rate controlling steps, rate multiplicity, long transients, and/or oscillatory phenomena. The origins of such phenomena are rooted in some of the central issues of catalysis, including adsorbate interactions, reaction-transport interactions, and surface structure and chemical transformations such as reconstruction and oxidationreduction. The project has both a kinetic modeling/mechanistic sequence development objective and a catalyst development objective.

The first objeclive is to formulate kinetic models based on sound surface chemistry for these oxidation reactions which can predict the observed steady-state and dynamic featuris. Successfully meeting this main objective requires an approach which integrates experiments and theoretical modeling. Our research cnuples basic kinetic measurements. in situ infrared monitoring of the catalyst surface, mechanistic sequence and kinetic model development, and nonlinear and numerical analyses. The 'best' model should be able to predict all the experimentally measured features, including the basic kinetic trends spanning a wide range of temperature and pressure (e.g., apparent reaction orders and activation energy), the location and shape of the operating condition region for which the rate is multivalued or periodic, trends in the adsorbed and/or solid state composition, and, when combined with descriptions of heat and mass transport processes, the key reactiontransport interactions.

The second objective is to develop bifunctional catalysts for the selective oxidation of hydrocarbons using insight gainer. from studies of the noble metal and transition metal oxide catalyzed oxidations. Our aim is to synthesize and characterize catalysts comprised of noble metals supported on active oxide layers. These bifunctional catalysts combine the high activity of the noble metal with the selectivity of the metal oxide. Example systems of interest include the use of $\mathrm{Pd} / \mathrm{V}_{2} \mathrm{O}_{5}$ to carry out the partial oxidation of ethylene to acetaldehyde while minimizing carbon oxide formation, and of $\mathrm{Pt} / \mathrm{CeO} / \mathrm{Al}_{2} \mathrm{O}_{3}$ to carry out the complete oxidation of methanol to $\mathrm{CO}_{2}$ while minimizing $\mathrm{CO}$ formation.

\section{Accomplishments During Second Year of Project}

In the past year we have focused our efforts on thret items which are now summarized.

\section{- Development of Fourier transform infrared emission spectroscopy to monitor near IR under reaction conditions: ethylene oxidation on $\mathrm{V}_{2} \mathrm{O}_{5}$.}

A key aspect of this project is to develop Fourier transform infrared emission spectroscopy (FITRES) as an in situ probe of the catalysi surface. The principal motivation is to monitor changes in the composition of a metal oxide during a hydrocarbon oxidation, and, if possible, adsorbed species as well. The coupling between oxidation and reduction of a particular metal oxide is a crucial process in determining the activity and selectivity. Moreover, the interaction of the reaction exothermicity and redox chemistry can lead to complex steady state features (e.g., multiplicity) and dynamic behavior (e.g., long 
transients, oscillations. Thus, knowledge of the catalyst composition under reaction conditions can provide insight into the identification of active sites and their reactivity.

In the past year we have successfully demonstrated the use of FTIRES as an in situ catalyst surface probe (Sullivan et al., 1992). In recent months we have focused our efforts on near-IR monitoring of $\mathrm{V}_{2} \mathrm{O}_{5}$ during reaction between ethylene and oxygen (to acetaldehyde and carbon oxides). This reaction was chosen because of the trade-off between selectivity and activity, and the redox chemistry involving the vanadium oxides. Our goal is to correlate changes in the oxide surface composition with activity and selectivity, while spanning a wide range of operating conditions (catalyst temperature, ethylene/oxygen feed ratio). To this end, in the past year a dedicated kinetics/FTIRES experiment has been constructed, a simplified schematic of which is shown in Figure 1. Detailed kinetics data are obtained in the isothermal packed bed microreactor. FTIRES Spectra are obtained in the in situ cell. Our decision to get the rate and spectra data in different units was necessitated by the minute anount of powdered catalyst that must be used in the emission cell. Thus, differential rates are obtained with the the microreactor setup. The same gas is flowed over the catalyst sample held at the same temperature within the cell for in situ emission characterization of the surface.

Figures 2 and 3 show representative spectra of the $\mathrm{V}_{2} \mathrm{O}_{5}$ in different atrnospheres and temperatures. The fully oxidized sample has a sharp peak at $1030 \mathrm{~cm}^{-1}$ and a broader one at $800-850 \mathrm{~cm}^{-1}$ (Fig. 2). These peaks are assigned to terminally-bonded $V=0$ and $\mathrm{V}$ $\mathrm{O}-\mathrm{V}$, respectively. In contrast, a severely reduced sample shows no features (Fig. 2). A partially reduced sample has an additional peak at $915 \mathrm{~cm}^{-1}$ (Fig. 3). These initial results are encouraging since they imply a correlation between the IR features and the degree of surface oxidation. We hope to more specifically link the IR features to composition by carrying out $e x$ situ chemical analyses of the vanadium oxide mixture containing $\mathrm{V}^{5+}, \mathrm{V}^{4+}$, and V3+ (following Niwa and Murakami, 1982). Presently we are collecting detailed kinetics data to map out conditions of maximum acetaldehyde yield. Below some more details are provided about work planned for the upcoming year.

\section{- Kinetics study of methanol oxidation on supported Pt catalysts.}

At the same time we are commencing with a detailed kinetics study of $\mathrm{Pt}$-catalyzed methanol oxidation. This work follows our detailed study of Pt-catalyzed CO oxidation at earlier phases in this research project. In the past year we have constructed a second microreactor setup (see Figure 4). This part of the research project involves detailed kinetic model development. To this end, the experiment permits the spanning of a wide range of rnethanol/oxygen feed ratios and catalyst temperatures. Our initial results reveal an interesting product selectivity issue: $\mathrm{A}$ methanol-rich feed the yield of $\mathrm{CO}_{2}$ exhibits a maximum at an intermediate temperature. This appears to be due to an increasing desorption rate of $\mathrm{CO}$ as temperature increases (i.e., the $\mathrm{CO}$ yield is an increasing function of temperature). The key issues of this study are the following:

- Identification of conditions of maximum yield of $\mathrm{CO}_{2}$ (complete oxidation is desired)

- Modification of catalyst formulation in order to inhibit $\mathrm{CO}$ desorption - here we plan to examine different supports which might reduce the undesired production of $\mathrm{CO}$ at high temperatures. For example, the addition of cerium oxide or of vanadium oxide may provide oxygen storage/supply capabilities. Under oxygenlean conditions oxygen provided by the oxide may be used to oxidize $\mathrm{CO}$ produced by the partial oxidation of methanol on the Pt crystallites. 


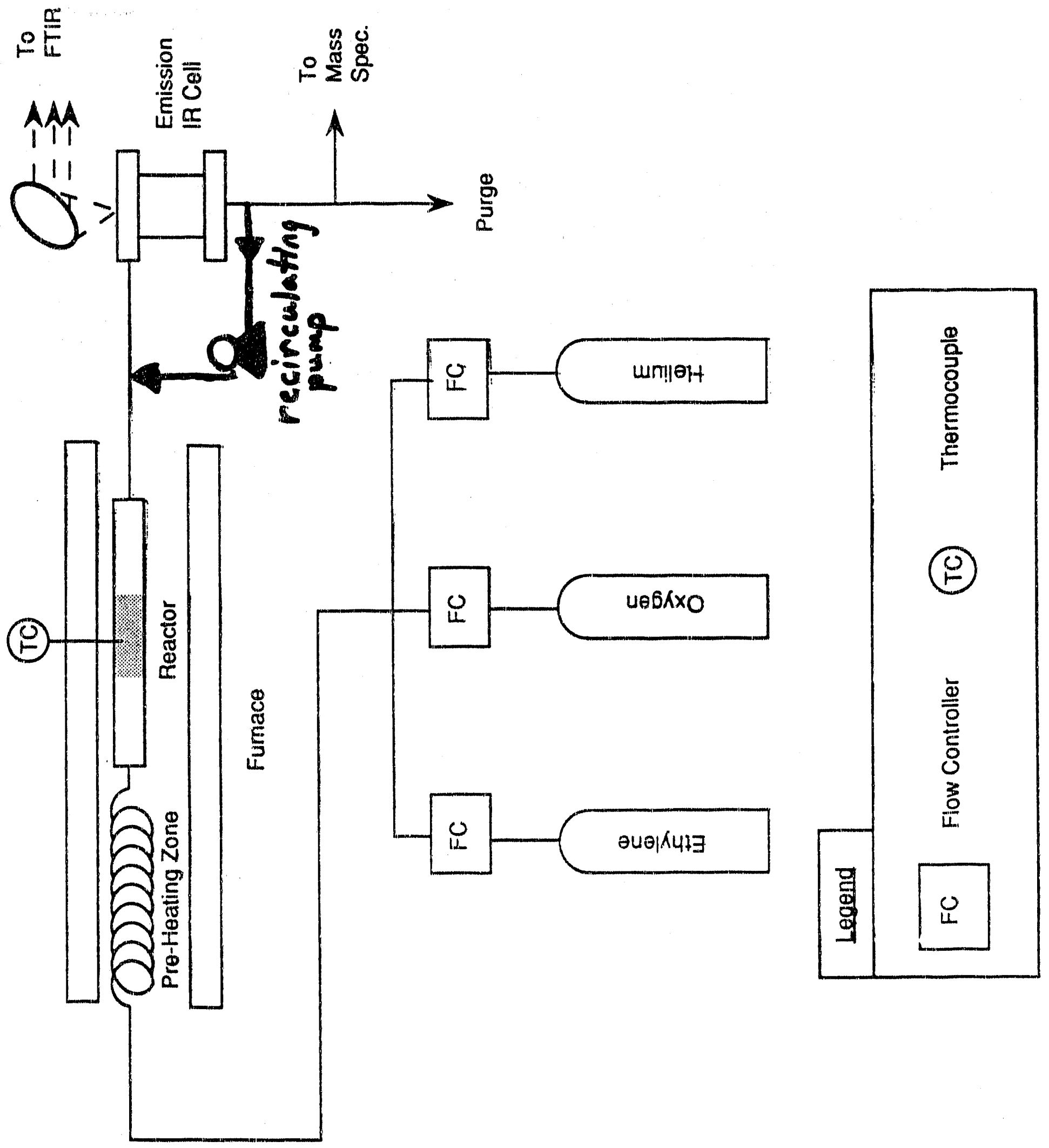




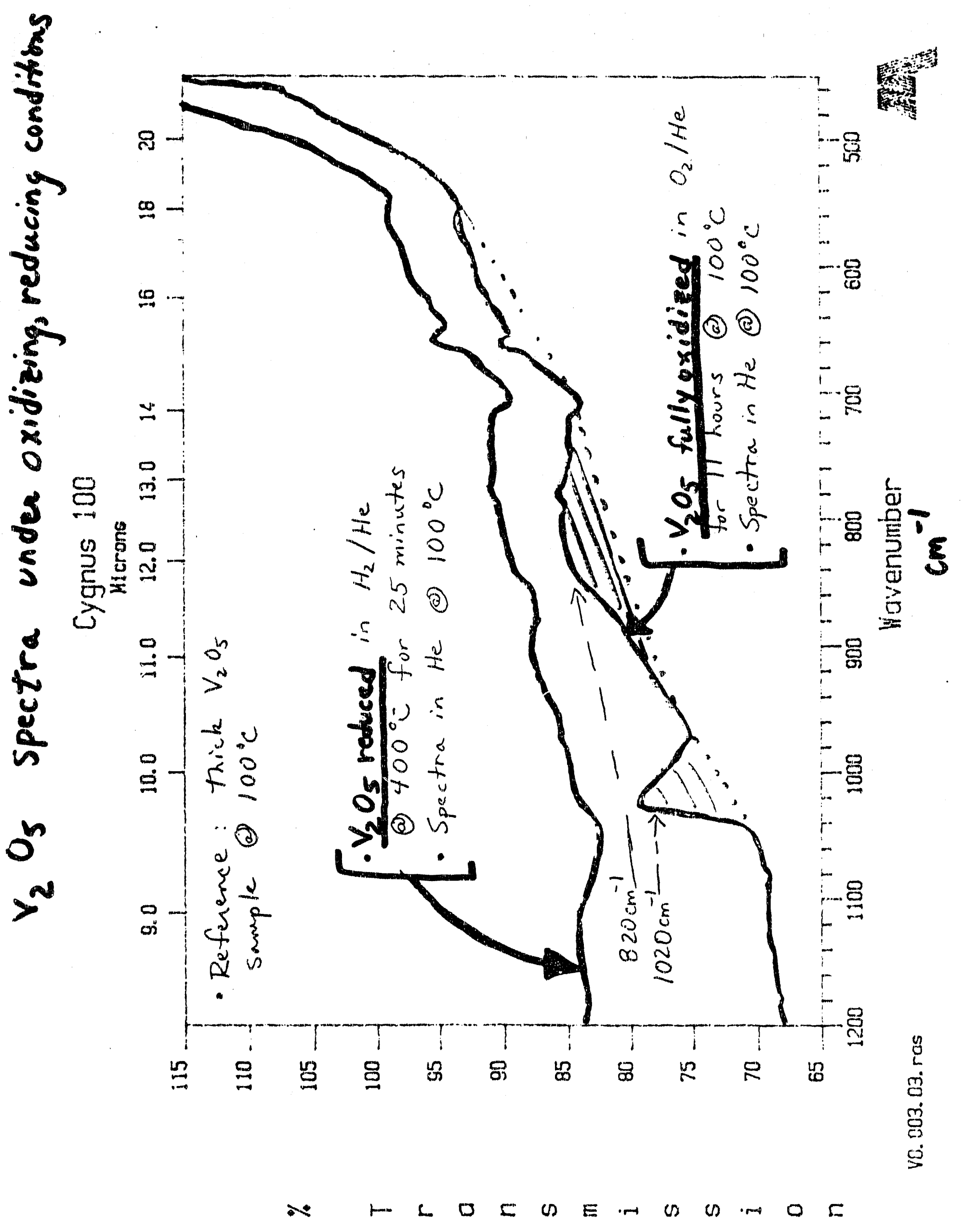




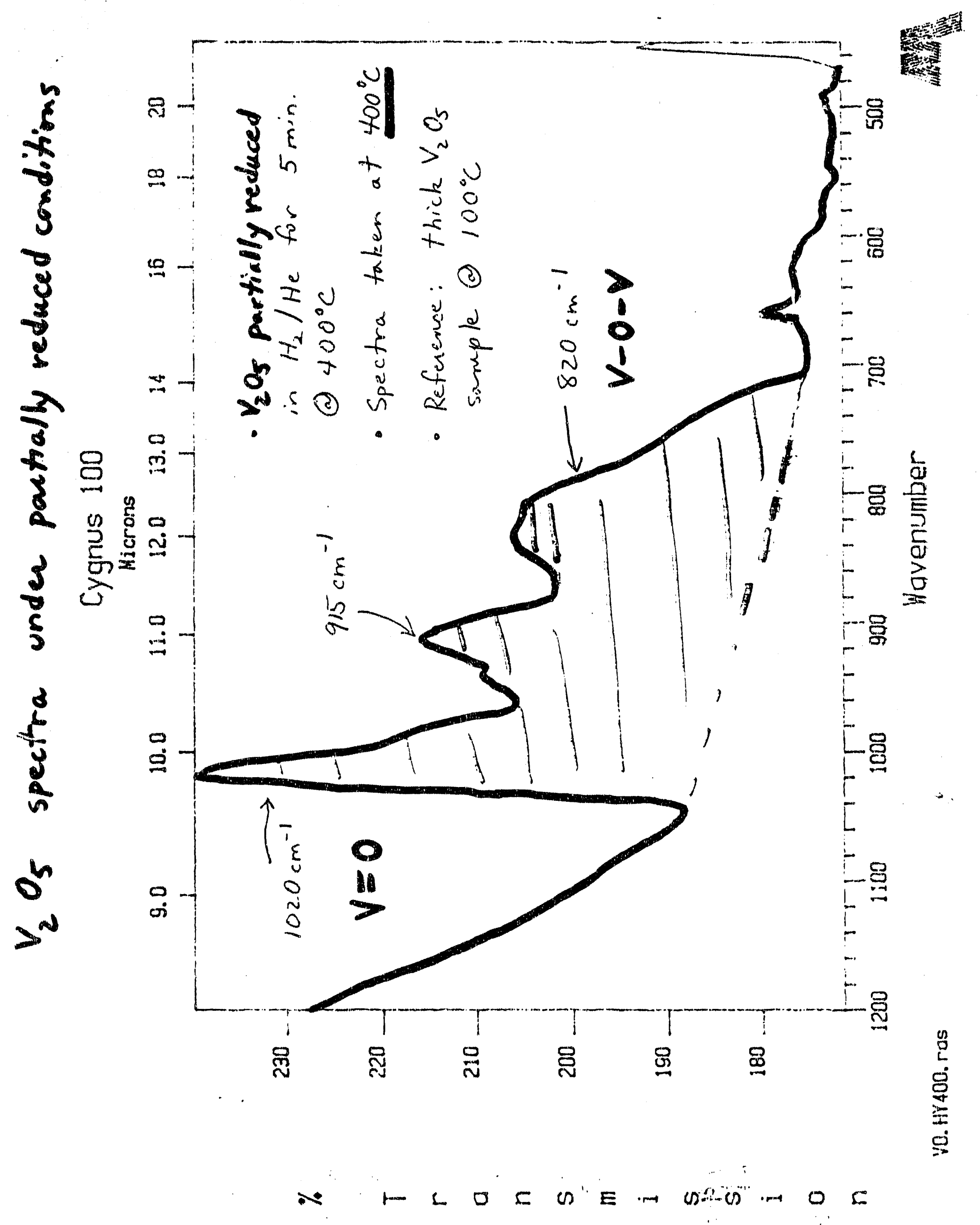


- Identification of key surface species during reaction - our plan is to use FTIR transmission spectroscopy to resolve the controversy of whether carbon oxide formation proceeds through an adsorbed $\mathrm{CO}$, formaldehyde, or methoxy species.

Our plans for the upcoming year are outlined below.

- Comparative kirstics study of CO oxidation on $P t, P d$, and $R h$.

This part of the project is one final phase of our study of $\mathrm{CO}$ oxidation on noble metal catalysts. Models which we have developed for $\mathrm{CO}$ oxidation on $\mathrm{Pt}$ are currently being tested and modified in order to help explain the kinetic differences observed with $\mathrm{Pd}$ and Rh. Rate data obtained by Coulston and Haller (1591) on $\mathrm{Pt}, \mathrm{Pd}$, and $\mathrm{Rh}$ foils reveal distinct differences in the location of the maximum in the dependence of rate on catalyst temperature, and of apparent reaction orders beyond the maximum. Our approach is to formulate the simplest possible revisions in the Pt kinetic model that will explain the trends.

To date, computer codes have been written to carry out the data regression and analysis. Details for the completion of this problem are provided below.

\section{Plans for the Third Year of Project}

An outline for work planned in the upcoming year is provided below.

\section{- Kinetics/FTIRES study of ethylene oxidation on vanadium oxide}

- Completion of FTIRES spectra analysis of vanadium oxide or wide range of feed ratios (ethylene: oxygen) and catalyst temperatures.

- Completion of ex situ chemical analysis of vanadium oxide: This step is intended to correlate the near-IR spectra features with a more quantitative assessment of the degree of oxidation of the vanadium oxide.

- Completion of kinetics study of ethylene oxidation on vanadium oxide for the same range of feed ratios (ethylene: oxygen) and catalyst temperatures.

- Development of mechanistic picture of olefin oxidation on vanadium oxide: Knowledge of the vanadium oxide surface composition as a function of the activity and selectivity will be the basis for this step.

\section{- Kinetic study of Pt-catalyzed methanol oxidation}

- Completion of kinetics study with differential reactor: Reaction orders and apparent activation energies will be obtained over a wide range of feed ratios and temperatures for a $\mathrm{Pt} / \mathrm{Al}_{2} \mathrm{O}_{3}$ catalyst. The $\mathrm{Pt} / \mathrm{Al}_{2} \mathrm{O}_{3}$ catalyst kinetic results will serve as the base comparison to modified catalysts. Particular attention will be placed on rate multiplicity and oscillations which have been known to occur during this reaction.

- Formulation of candidate mechanistic sequences for methanol oxidation on $\mathrm{P}_{1} \mathrm{Al}_{2} \mathrm{O}_{3}$ : Our approach here will be similar to the method w'e developed for CO oxidation on $\mathrm{Pt}$. 
- Design and construction of transmission IR cell and flow system: Initial steps towards carrying out an in situ FTIR study will be completed. The timing for this step requires that we wait for the completion of the ethylene oxidation study.

- Comparative kinetics study of CO oxidation on Pt, Pd, and Rh.

Regression analysis of the Coulston and Haller kinetic data will be carried out using several candidate kinetic models. Possible revisions of the $\mathrm{CO}$ oxidation on $\mathrm{Pt}$ model include the incorporation of a reversible metal oxide formation step; i.e., there is evidence that $\mathrm{Pd}$ and $\mathrm{Rh}$ more easily form these less active oxide species. A successful comparison should help to explain the pitfalls in going too far in generalizing the $\mathrm{CO}$ oxidation reaction on the entire family of noble metals.

\section{Graduate Students Participating in Project}

- David Sullivan - FTIRES/kinetics study of ethylene oxidation on $\mathrm{V}_{2} \mathrm{O}_{5}$. Dave will be completing his $\mathrm{PhD}$ thesis in the upcoming year.

- Andrew Oliveiro - Kinetics study of methanol oxidation on Pt; comparative kinetics of $\mathrm{CO}$ oxidation on $\mathrm{Pt}, \mathrm{Pd}, \mathrm{Rh}$

- New student (yet to be determined) - Will carry out development and analysis of bifunctional $\mathrm{Pd} / \mathrm{V}_{2} \mathrm{O}_{5}$ catalysts for ethylene oxidation.

\section{Publications and Presentations in the Past Year}

\section{Publications}

- Garske, M.E. and M.P. Harold, "Observed Kiretics of an Exothermic Reaction on a Temperature-Controlled Catalytic Wire," Chem. Eng. Sci., 47, no. 3, 623-644.

- Sullivan, D. H., W. C. Conner, and M. P. Harold, "Surface Analysis with FT-IR Emission Spectroscopy," J. Appl. Spectroscopy, 46, no. 5, 811-818.

\section{RTesentations}

- Harold, M.P., "Kinetics and Dynamics of Oxidation Reactions Invol,ing an Adsorbed CO Species," DOE Review of Catalysis Program, Gaithersburg, MD, 1992.

- Sullivan, D. H., W. C. Conner, and M. P. Harold, "Monitoring Oxidation-Reduction During Reaction with FTIR Emission Spectroscopy: Ethylene Oxidation on $\mathrm{V}_{2} \mathrm{O}_{5}$," to be presented in "Fundamentals of Oxide Catalysts" session at 1992 AIChE Meeting, Miami Beach.

\section{Proposed Budget for the Third Year of $x$ rojert}

The budget proposed for the period of 1/1/93 - 12/31/93 is attached. 

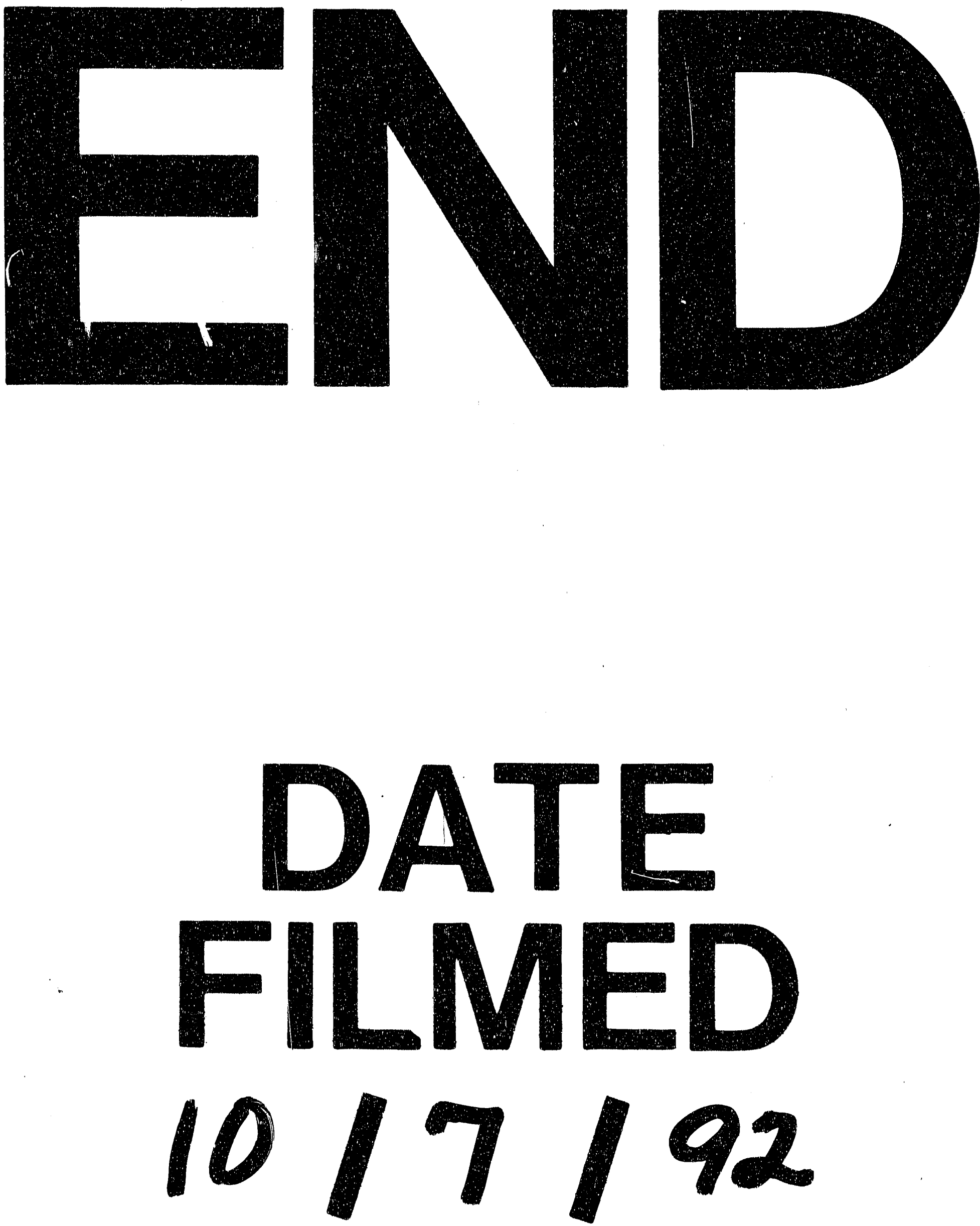
